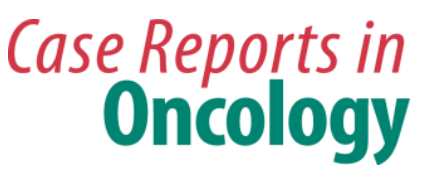

Case Rep Oncol 2017;10:694-698

DOI: $10.1159 / 000478976$

Publisned oninne: August 4, 2017
(C) 2017 The Author(s)

Published by S. Karger AG, Basel

www.karger.com/cro

This article is licensed under the Creative Commons Attribution-NonCommercial 4.0 International License (CC BY-NC) (http://www.karger.com/Services/OpenAccessLicense). Usage and distribution for commercial purposes requires written permission.

\title{
Solitary Skeletal Muscle Metastasis as First Site of Recurrence of Cervical Cancer: A Case Report
}

\author{
Indumathy Varadarajan ${ }^{\mathrm{a}} \quad$ Aparna Basu $^{\mathrm{b}}$ Sherri Besmer ${ }^{\mathrm{a}}$ \\ Jaganmohan Poli ${ }^{\mathrm{c}}$ Scott Richard ${ }^{\mathrm{d}}$ Michael Styler $^{\mathrm{a}}$ \\ ${ }^{a}$ Drexel University College of Medicine, Philadelphia, PA, USA; ${ }^{b}$ Henry Ford Medical \\ Center, Detroit, MI, USA; ${ }^{C}$ Hanhemann University Hospital, Philadelphia, PA, USA; \\ dJefferson Hospital, Philadelphia, PA, USA
}

\section{Keywords}

Cervical cancer · Gynecological cancer · Human papillomavirus · Metastasis · Musculoskeletal metastasis $\cdot$ Solitary metastasis

\begin{abstract}
Cervical cancer is the fourth most common cancer in women worldwide, with a large majority of prevalence (85\%) in developing countries. As of 2012, it accounts for $7.5 \%$ of all female cancer deaths. Despite its high prevalence, skeletal muscle metastasis from cervical cancer is extremely uncommon. In our extensive literature search, we were able to find only 8 cases where skeletal muscle metastasis was the only site of recurrence. We report a case of a 52year-old African-American woman with a past medical history of cervical cancer (stage IIIB) who presented with pain and swelling in her left upper arm over the preceding 2 months. MRI of the left upper arm showed a solid well-circumscribed mass measuring $7.0 \times 2.8 \times 2.5$ $\mathrm{cm}$, deep to the biceps. Biopsy of the mass revealed a metastatic squamous cell carcinoma that was p16-positive. PET scan showed that the lesion was the sole site of metastasis. She received local radiation with concurrent chemotherapy. Follow-up MRI 6 months after the completion of therapy showed resolution of the mass. She has remained disease-free for the last 24 months as evidenced by a PET/CT scan in May 2016. In this case report, we discuss the role of imaging and pathology in the diagnosis of a solitary metastatic lesion. This case also emphasizes the importance of a close follow-up which aids in early intervention, increasing overall survival.




\section{Case Reports in Oncology}

Varadarajan et al.: Solitary Skeletal Muscle Metastasis as First Site of Recurrence of Cervical Cancer: A Case Report

\section{Introduction}

The incidence of skeletal muscle metastases in solid malignancies is reported to be less than $1 \%$ of all metastases, despite the fact that skeletal muscle accounts for nearly $50 \%$ of the total body weight. Skeletal muscle metastasis as the only site of recurrence of cervical carcinoma is particularly rare. To our knowledge, only 8 cases have been reported in the literature thus far $[1,2]$. We report the 9 th case of a solitary skeletal muscle metastatic lesion from cervical cancer.

\section{Case Report}

A 51-year-old woman presented to the hospital with swelling in her left arm, which had been increasing in size over the preceding 2 months. She was diagnosed with stage IIIB cervical cancer in April 2012 and was treated with weekly cisplatin and concurrent radiation. She was subsequently lost to follow-up after her treatment until the above presentation 2 years later. On examination, she was noted to have a $7 \times 3 \mathrm{~cm}$ well-circumscribed mass in the antero-medial aspect of the left forearm, which was minimally tender, nonmobile and not attached to the overlying skin, but changed in size with muscular contraction. She did not have any other masses or palpable lymph nodes. A vaginal examination did not reveal local recurrence. She had a normal complete blood count and biochemical profile. She was HIV negative. A contrast-enhanced MRI of the left arm (Fig. 1) revealed a $7.0 \times 2.8 \times 2.5 \mathrm{~cm}$ tumor, deep to the biceps and brachialis, abutting the humeral cortex without apparent bone invasion. A subsequent biopsy revealed large polygonal cells with abundant eosinophilic cytoplasm, typical for squamous cell carcinoma within the deep tissue of the left arm (Fig. 2). The cells had a strong and diffuse staining pattern with p16 immunohistochemical staining which was consistent with a human papillomavirus-driven lesion. A staging PET/CT scan showed that the lesion in her arm was the sole site of metastasis and she had no evidence of local recurrence. Since the tumor was seen to be abutting the cortex of the humerus, limbsparing surgery was not felt to be feasible. Therefore, she was treated with concurrent chemoradiation with weekly cisplatin. She responded extremely well to therapy (Fig. 3) and has remained disease-free for 24 months since completing the therapy as evidenced by a PET/CT scan on May 26, 2016.

\section{Discussion}

The prevalence of skeletal muscle metastasis ranges from 0.03 to $5.6 \%$ in autopsy series of patients with cancer [3-5]. However, these metastases are rarely detected radiographically as most of these tumors are micrometastatic deposits and patients are often asymptomatic. Surov et al. [6] analyzed 5,172 patients with metastasized cancer and identified 61 patients (with a total of 80 lesions) with skeletal muscle metastases on CT or MRI. Genital tumors were found to be the most common tumors to metastasize to the skeletal muscle $(24.6 \%)$, followed by gastrointestinal tumors, urologic tumors, and malignant melanomas [6]. Several hypotheses have been postulated to explain the rarity of skeletal muscle metastasis. Contractile movement of the skeletal muscle and constant fluctuations in intramuscular blood pressure may act as mechanical barriers for tumor implantation. The local production of lactic acid, with a relative lack of oxygen can also prevent tumor proliferation. Prote- 


\section{Case Reports in Oncology}

Varadarajan et al.: Solitary Skeletal Muscle Metastasis as First Site of Recurrence of Cervical Cancer: A Case Report

ase inhibitors located in the skeletal muscle cell basement membrane may play a vital role in preventing invasion of tumor cells as well. Immune-mediated antitumor activity by lymphocytes and natural killer cells within the skeletal muscle are other postulated theories that help reduce the incidence of metastasis [7].

A solitary metastatic lesion from a remote primary cervical cancer is particularly uncommon. The rate of recurrence decreases with an increasing disease-free interval. If a patient has a disease-free interval of more than 5 years, the recurrence is approximately $4 \%$. The incidence of recurrence increases with the stage of initial diagnosis, and is $8.5 \%$ overall for stage III disease [8].

Differentiating skeletal muscle metastasis and soft tissue sarcoma radiographically can be difficult. Though needle biopsy is needed for a definite diagnosis, radiological imaging can provide valuable information. Compared with MRI, a plain radiogram and CT are of little value with regard to the characterization of the mass. MRI with intravenous gadolinium enhancement can be helpful when planning the biopsy of these lesions, as it is useful to evaluate the vascularity of the tumor. Extensive peritumoral enhancement associated with central necrosis is one of the characteristic features of the skeletal muscle metastasis. Other than the pathological features that suggest squamous cell malignancy, positive staining for the p16 immunohistochemical stain is pathognomonic for a human papillomavirus-driven lesion $[9,10]$.

The general clinical outcome of patients with isolated skeletal metastasis is poor as suggested by the previous case reports. This is most likely due to the presence of more diffuse, occult metastasis. A palliative approach is usually taken in these patients. However, patients with isolated distant metastatic disease may be amenable to local treatment. Treatment could include surgical resection with or without concurrent radiation, or radiation with or without concurrent chemotherapy. Our patient had a single skeletal lesion in her left arm with no evidence of any other metastatic lesions. There have been no established guidelines for the management of these situations due to the dearth of such occurrences.

This experience emphasizes the importance of dedicated long-term follow-up in cervical cancer survivors. Remote recurrence of this disease, though uncommon, does occur. With the robust expansion of targeted therapies, longer periods of overall survival are feasible [11]. Patients with isolated recurrences may even be cured with aggressive therapy.

\section{Statement of Ethics}

The authors have no ethical conflicts to disclose.

\section{Disclosure Statement}

The authors have no conflicts of interest to declare.

\section{References}

1 Ferrandiana G, Salutari V, Testa A, Zannoni GF, Petrillo M, Scambia G: Recurrence in skeletal muscle from squamous cell carcinoma of the uterine cervix: a case report and review of literature. BMC Cancer 2006;6:169.

2 Karunanithi G, Sethi P, Reddy KS, Rani PR: Skeletal muscle metastasis from carcinoma cervix: a case report. J Gynecol Oncol 2010;21:196-198. 


\section{Case Reports in Oncology}

\begin{tabular}{l|l}
\hline Case Rep Oncol 2017;10:694-698 \\
\hline DOI: 10.1159/000478976 & $\begin{array}{l}\text { (c) 2017 The Author(s). Published by S. Karger AG, Basel } \\
\text { www.karger.com/cro }\end{array}$ \\
\hline
\end{tabular}

Varadarajan et al.: Solitary Skeletal Muscle Metastasis as First Site of Recurrence of Cervical Cancer: A Case Report

- Hasegawa S, Sakurai Y, Imazu H, Matsubara T, Ochiai M, Funabiki T, Suzuki K, Mizoguchi Y, Kuroda M, Kasahara M: Metastasis to the forearm skeletal muscle from an adenocarcinoma of the colon: report of a case. Surg Today 2000;30:1118-1123.

4 Willis RA: The Spread of Tumours in the Human Body. London, Butterworth, 1952.

5 Nabeyama R, Tanaka K, Matsuda S, Iwamoto Y: Multiple intramuscular metastases 15 years after radical nephrectomy in a patient with stage IV renal cell carcinoma. J Orthop Sci 2001;6:189-192.

-6 Surov A, Hainz M, Holzhausen HJ, et al: Skeletal muscle metastases: primary tumours, prevalence, and radiological features. Eur Radiol 2010;20:649-658.

-7 Sudo A, Ogihara Y, Shiokawa Y, Fujinami S, Sekiguchi S: Intramuscular metastasis of carcinoma. Clin Orthoped 1993;296:213-2178.

8 Takehara K, Shigemasa K, Sawasaki T, Naito H, Fuiji T: Recurrence of invasive cervical carcinoma more than 5 years after initial therapy. Ostet Gynecol 2001;98:680-684.

-9 Cioffi-Lavina M, Chapman-Fredricks J, Gomez-Fernandez C, Ganjei-Azar P, Manoharan M, Jorda M: P16 expression in squamous cell carcinomas of cervix and bladder. Appl Immunohistochem Mol Morphol 2010;18:344-347.

-10 Corbalan-Velez R, Oviedo-Ramirez I, Ruiz-Macia JA, Conesa-Zamora P, Sanchez-Hernandez M, MartinezBarba E, Brufau-Redondo C, Lopez-Lozano JM: Immunohistochemical staining of p16 in squamous cell carcinomas of the genital and extragenital area. Actas Dermosifiliogr 2001;102:439-477.

-11 Tewari KS, Sill MW, Long HJ III, Penson RT, Huang H, Ramondetta LM, Landrum LM, Oaknin A, Reid TJ, Leitao MM, Michael HE, Monk BJ: Improved survival with bevacizumab in advanced cervical cancer. N Engl J Med 2014;370:734-743.
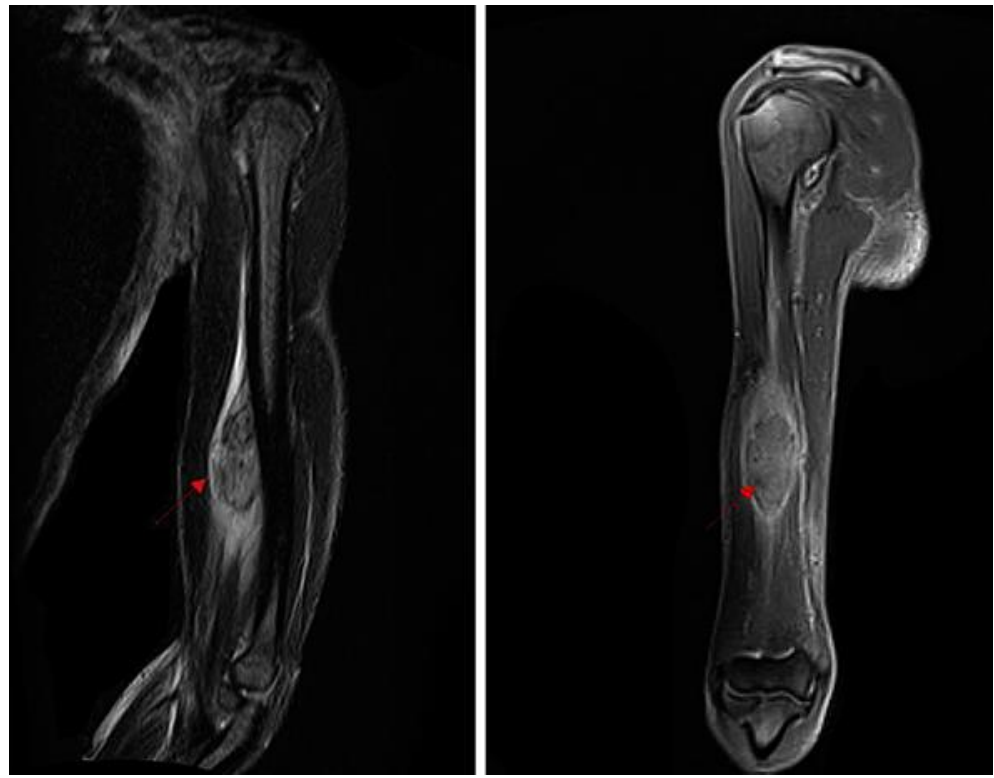

Fig. 1. Pretreatment MRI (December 2014). Contrast-enhanced T1-weighted images with sagittal and coronal section. 


\section{Case Reports in Oncology}

Varadarajan et al: Solitary Skeletal Muscle Metastasis as First Site of Recurrence of Cervical Cancer: A Case Report
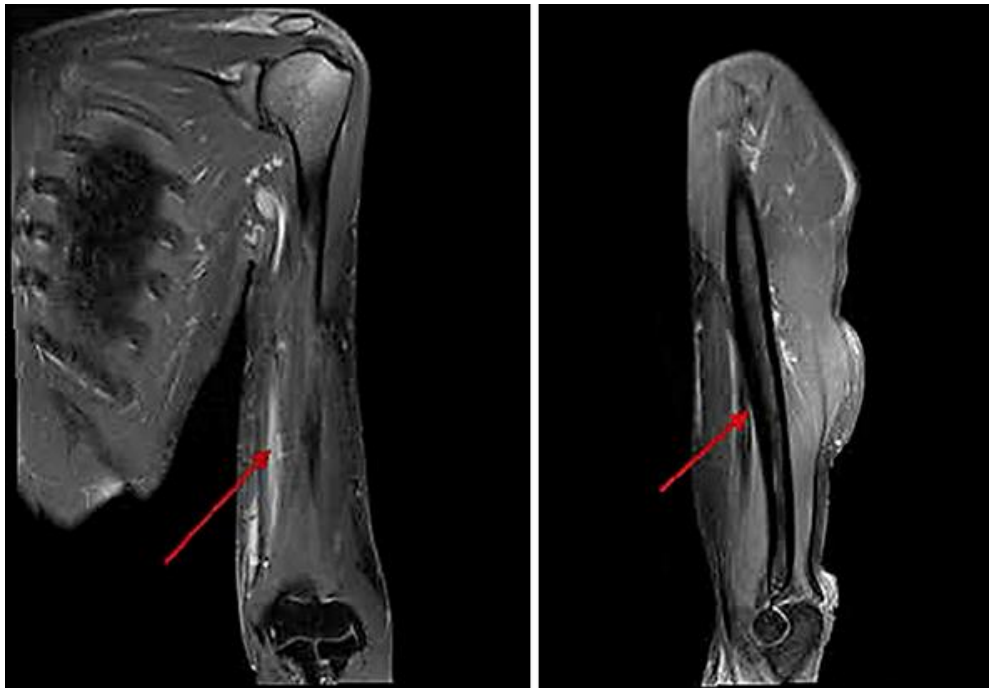

Fig. 2. Posttreatment MRI (September 2015). Coronal and sagittal section.
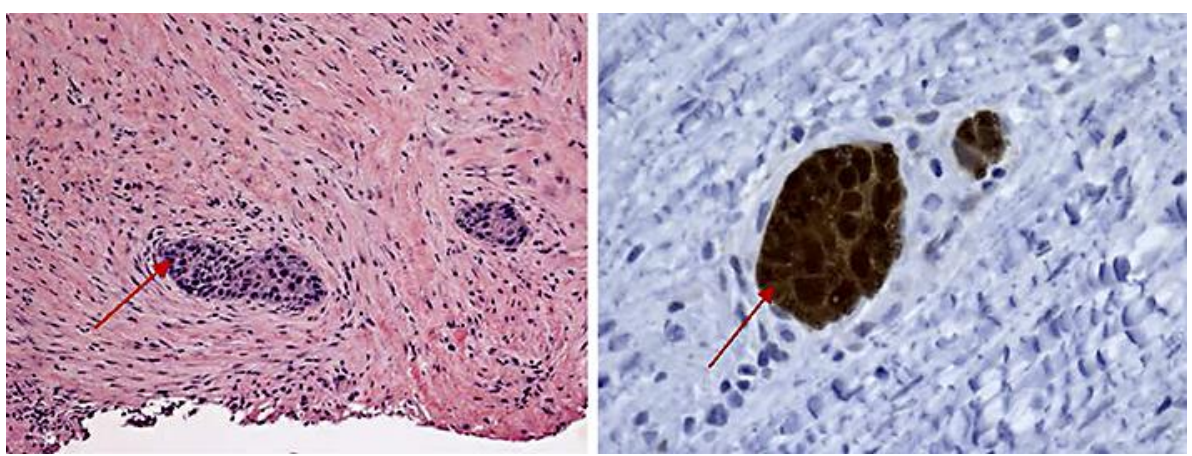

Fig. 3. Nests of malignant squamous cells within a background of mostly fibrous tissue with atrophic muscle and chronic inflammation (right panel). The malignant squamous cells demonstrate strong and diffuse positivity for p16 immunohistochemical stain (left panel). 